\title{
Interstitial fibrosis and microvascular disease of the heart in uremia: amelioration by a calcimimetic
}

\author{
Nadezda Koleganova, ${ }^{1,2}$, Grzegorz Piecha ${ }^{1,2,3}$, Eberhard Ritz ${ }^{2}$, Raffi Bekeredjian ${ }^{4}$, Peter Schirmacher ${ }^{1}$, \\ Claus Peter Schmitt ${ }^{5}$ and Marie-Luise Gross ${ }^{1}$
}

In patients with chronic renal failure, the heart undergoes remodeling, characterized by hypertrophy, fibrosis, and capillary/myocyte mismatch. In this study, we observed the effects of the calcimimetic agent R-568 on microvascular disease and interstitial fibrosis of the heart. Three-month-old male Sprague-Dawley rats were randomized to subtotal nephrectomy (SNX) or sham operation and subsequently received vehicle or R-568 under two experimental protocols, one for 1 month and the other for 3 months. Echocardiography, capillary length density, volume density of interstitial tissue, and immunohistochemistry and western blots (calcium-sensing receptor, collagen I and III, transforming growth factor (TGF)- $\beta$, mitogen-activated protein kinases, and nitrotyrosine) were assessed. After SNX, weight and wall thickness of the left and the right ventricle were elevated. The ratio of heart to body weight and interventricular septum thickness were not changed by R-568 treatment. The left ventricle fractional shortening (by echocardiography) was lower in SNX; this was ameliorated by R-568. Reduced capillary length density and increased interstitial fibrosis in SNX were improved by R-568, which also reduced the expression of TGF- $\beta$, and collagen I and III. The calcimimetic increased the activation of ERK-1/2, normalized p38 and JNK signaling, and prevented oxidative stress. We conclude that lowering parathyroid hormone with a calcimimetic significantly improves cardiac histology and function but not the left ventricular mass in SNX. Laboratory Investigation (2009) 89, 520-530; doi:10.1038/labinvest.2009.7; published online 2 February 2009

KEYWORDS: secondary hyperparathyroidism; chronic renal failure; cardiac remodeling; calcimimetics

Cardiovascular disease is the primary cause of death in patients with chronic kidney disease. ${ }^{1}$ As the glomerular filtration rate decreases, the risk of coronary events increases strikingly. ${ }^{2}$ In uremic patients, marked remodeling of the heart is observed. ${ }^{3}$ In experimental uremia, capillary/myocyte mismatch is observed, presumably reducing perfusion reserve and oxygen supply. ${ }^{4,5}$

Secondary hyperparathyroidism is a common feature of chronic kidney disease. ${ }^{6}$ The more adverse cardiovascular outcomes in patients with high parathyroid hormone (PTH) concentrations and its improvement by parathyroidectomy ${ }^{7,8}$ are presumably explained not only by the effects on calcemia and phosphatemia. Direct adverse effects of PTH on cardiac function $^{9,10}$ and on cardiac fibrosis, as well as on microvessel disease, ${ }^{11,12}$ have also been documented.

Calcimimetics act on the calcium-sensing receptor (CaSR) and lower PTH without increasing calcium levels. ${ }^{13}$ These small compounds allosterically modulate the CaSR, making it more responsive to $\mathrm{Ca}^{2+}$. The beneficial effects of calcimimetics on heart morphology, comparable with that of parathyroidectomy, were earlier suggested by a study in experimental uremia, ${ }^{14}$ but no information is available on cardiac function and signaling pathways. We have shown earlier that the calcimimetic R-568 decreases albuminuria in subtotally nephrectomized rats. ${ }^{15}$

Therefore, it was the purpose of this study to further evaluate the effects of the calcimimetic R-568 on cardiac mass, contractility, capillary density, interstitial fibrosis, and the expression of pathophysiologically relevant molecules in subtotally nephrectomized rats.

\section{MATERIALS AND METHODS Animals and Subtotal Nephrectomy}

All animal procedures were approved by the local ethics committee for animal experiments. Twelve-week-old male Sprague-Dawley rats (mean body weight $335 \pm 79 \mathrm{~g}$; Charles

\footnotetext{
${ }^{1}$ Insitute of Pathology, University of Heidelberg, Heidelberg, Germany; ${ }^{2}$ Department of Internal Medicine, University of Heidelberg, Heidelberg, Germany; ${ }^{3}$ Department of Nephrology, Endocrinology and Metabolic Diseases, Medical University of Silesia, Katowice, Poland; ${ }^{4}$ Department of Cardiology, University of Heidelberg, Heidelberg, Germany and ${ }^{5}$ University Children's Hospital, University of Heidelberg, Heidelberg, Germany

Correspondence: Dr N Koleganova, MD, Department of Pathology, University of Heidelberg, Im Neuenheimer Feld 220/221, Heidelberg D-69120, Germany. E-mail: nad_ko@gmx.de
}

Received 16 October 2008; revised 4 December 2008; accepted 5 December 2008 
River Co., Sulzfeld, Germany) were housed at a constant room temperature $\left(21 \pm 1^{\circ} \mathrm{C}\right)$ and humidity $(75 \pm 5 \%)$, and exposed to a 12-h light-on and 12-h light-off cycle. The animals had free access to water and were fed a standard rodent diet $(19.0 \%$ protein, $4.0 \%$ fat, $0.90 \%$ calcium, and $0.70 \%$ phosphorus; Ssniff, Germany). After a 7-day adaptation period, the rats were randomly allotted to either a twostep subtotal nephrectomy (SNX) (the removal of right kidney and the weight-controlled removal of cortical tissue of the left kidney- $66 \%$ of the weight of the right kidney) or sham operation (sham-op).

\section{Long-Term Experiment (12 Weeks, Ad Libitum)}

After the operation, SNX and sham-op animals were randomly allocated to the following treatments:

1. Sham-op, treated with vehicle (sham-op control, $n=16$ );

2. SNX, treated with vehicle (SNX control, $n=17$ ); and

3. SNX, treated with R-568 (SNX + R568, $n=20)$.

The calcimimetic agent R-568 (Amgen Inc., Thousand Oaks, CA, USA) was dissolved in $10 \%$ 2-hydroxypropyl$\beta$-cyclodextrin (Sigma-Aldrich, Munich, Germany) and administered daily (17 mg per $\mathrm{kg}$ body weight) by a subcutaneous injection as described earlier. ${ }^{15}$ The control animals received vehicle alone. Body weight and blood pressure (by tail plethysmography in conscious animals $24 \mathrm{~h}$ after the last dose) were measured at regular intervals. At weeks 4 and 12, the animals were kept in metabolic cages for 24-h urine collection.

\section{Short-Term Experiment (4 Weeks, Pair-Feeding)}

To exclude a potential confounding effect induced by differences in food consumption, we performed an additional short-term experiment. After the operation, the animals were pair-fed (sham-op vs SNX + vehicle $v s \mathrm{SNX}+\mathrm{R}-568$ ) and randomly allocated to the following treatments:

1. Sham-op, treated with vehicle $(n=10)$;

2. SNX, treated with vehicle $(n=10)$; and

3. SNX, treated with R-568 $(n=10)$.

R-568 was administered as described above. At week 4, echocardiography was performed and 24-h urine samples were collected for albuminuria. After intra-aortic blood pressure measurement and blood sampling, the animals were sacrificed.

\section{Urinary Albumin Measurements and Blood Analysis}

Urinary albumin excretion was measured using a rat-specific sandwich ELISA. ${ }^{16}$ Serum creatinine, calcium, and phosphorus were measured by standard laboratory methods and serum PTH by the two-antibody method using a rat iPTH ELISA kit (Immutopics Inc., San Clemente, CA, USA). Serum angiotensin II was measured using an EIA kit (Peninsula Laboratories LLC, San Carlos, CA, USA).

\section{Tissue Preparation}

The abdominal aorta was catheterized under ketamine/xylazine anesthesia (100 and $3 \mathrm{mg} / \mathrm{kg}$, respectively), blood samples were taken, blood was washed out using $0.9 \% \mathrm{NaCl}$, and the experiment was terminated by retrograde aortic perfusion with $3 \%$ glutaraldehyde for morphometric and stereological investigations or ice-cold $0.9 \% \mathrm{NaCl}$ for molecular investigations. Perfusion pressure was kept constant at $120 \mathrm{~mm} \mathrm{Hg}$.

After perfusion with glutaraldehyde, the hearts were removed and weighed. For uniformly random tissue sampling and morphometry, the orientator method was used. Eight pieces were embedded in Epon-Araldite; semi-thin sections $(1 \mu \mathrm{m})$ were cut, stained with methylene blue/basic fuchsin, and examined using light microscopy with oil immersion and phase contrast (magnification of $\times 1000$ ).

After perfusion with ice-cold $0.9 \% \mathrm{NaCl}$, the hearts were divided into horizontal slices and snap-frozen in liquid nitrogen for western blotting or fixed in $4 \%$ formaldehyde for immunohistochemistry.

\section{Quantitative Stereology of the Heart}

The orientator method was used for the quantification of myocardial structures. ${ }^{17}$ All investigations were performed in a blinded manner (ie, the observer was unaware of the animal groups). The length density $\left(\mathrm{L}_{\mathrm{v}}\right)$ of capillaries (ie, the length of capillaries per unit tissue volume), and the volume density of cardiac capillaries and interstitial tissue were measured as described earlier. ${ }^{16,18}$ The intercapillary distance was calculated according to a formula by Henquell and Honig. ${ }^{19}$

Myocardial total collagen content was measured in sections stained with $0.1 \%$ Sirius red F3BA saturated in picric acid (a percent of Sirius-red-stained collagen area to the total myocardial area), using semi-automatic image analysis software (Optimas 6.0; Optimas Corp., Seattle, WA, USA).

The wall thickness and lumen diameter of intramyocardial arteries (diameter: 20-200 $\mu \mathrm{m}$ ) were determined planimetrically, using semi-automatic image analysis software (Optimas 6.0; Optimas Corp.) as described in detail elsewhere. ${ }^{20}$

\section{Immunohistochemistry and In Situ Hybridization}

Immunohistochemical analysis was carried out on paraffin sections using antibodies against CaSR (Affinity BioReagents, Golden, CO, USA), vascular endothelial growth factor (VEGF), transforming growth factor (TGF)- $\beta_{1}$, TGF- $\beta$ receptor type 1 and type 2 (Santa Cruz Biotechnology, Heidelberg, Germany), VEGF receptor type 1 and type 2 (Abcam, Cambridge, UK), collagen type I and type III, (BioTrend, Köln, Germany), nitrotyrosine (Upstate, New York, NY, USA), and prolyl-4-hydroxylase (Acris Antibodies, Hiddenhausen, Germany) by the streptavidin-biotin technique using alkaline phosphatase as the labeling enzyme. All antibodies had been tested for specificity in rats, and optimal concentration for staining was evaluated by testing different 
dilutions in a pilot study. Negative controls were performed by omitting the primary antibody.

The nonradioactive in situ hybridization for CaSR was performed as described earlier. ${ }^{21}$

The staining was analyzed by an investigator blinded with respect to the animal group using the following semiquantitative scoring system (0-4): 0 , no expression; 1 , weak expression; 2, moderate expression; 3 , strong expression; and 4 , extremely strong expression. Intraobserver error was $<5 \%$.

\section{Western Blotting}

Samples of myocardium from 8 to 9 animals per group were prepared by homogenization, and the protein concentration was assessed according to the Bradford method ${ }^{22}$ (Protein Assay Kit; Bio-Rad Laboratories, Munich, Germany). Equal amounts of protein $(100 \mu \mathrm{g})$ were electrophoresed in SDSPAGE gel and subsequently transferred to Immobilon-P membranes (Millipore Corp., Bedford, MA, USA). The membranes were blocked with $5 \%$ non-fat dried milk and then incubated with a primary antibody against CaSR, endothelial nitric oxide synthase (eNOS, Affinity Bioreagents), phosphorylated ERK-1/2 (p-ERK-1/2, Novus Biologicals, Littleton, USA), phosphoruslated JNK (p-JNK) phosphorylated p38 (p-p38), collagen I, VEGF, TGF- $\beta_{1}$ (Santa Cruz Biotechnology), inducible NOS (iNOS, BD Biosciences, Heidelberg, Germany), Heat Shock Protein-70 (Hsp-70, Assay Designs, Ann Arbor, USA), hypoxia inducible factor- $1 \alpha$ (HIF-1 $\alpha$, Chemicon, Millipore, Schwalbach, Germany), Matrix metalloproteinase (MMP)-1, MMP-2, tissue inhibitor of metalloproteinase (TIMP)-1, TIMP-2 (Calbiochem, Darmstadt, Germany), and collagen III (BioTrend). Horseradish peroxidase-conjugated secondary antibodies (Santa Cruz Biotechnology) were used, and were visualized by the ECL kit (GE Healthcare, Buckinghamshire, UK) according to the manufacturer's instruction. Specific bands were quantified by densitometric analyses using a Molecular Dynamics Personal Densitometer (EasyWin32, Herolab, Germany).

\section{In Vivo Assessment of Cardiac Function}

The left ventricular (LV) function was evaluated with transthoracic echocardiography in conscious pair-fed animals at week 4 using a $30-\mathrm{MHz}$ probe. The echocardiographer was blinded with respect to the treatment and control groups. A parasternal short-axis view was obtained for LV M-mode imaging at the papillary muscle level. Three independent Mmode images were used for six measurements of LV enddiastolic internal diameter (LVEDD), LV end-systolic internal diameter (LVESD), thickness of interventricular septum, and LV posterior wall (PWT) in two consecutive beats according to the American Society of Echocardiography. ${ }^{23}$ Fractional shortening (FS) was calculated as FS\% $=[($ LVEDD-LVESD $) /$ LVEDD] $\times 100$.

\section{Statistics}

Data are given as mean \pm s.d. For western blots, the vehicletreated sham-op group served as reference and mean value of individual measurements was set as $100 \%$. The value for each animal was expressed as manifold of reference. After testing for normal distribution, the ANOVA or Kruskal-Wallis test, as necessary, was used for analysis of variance. For the differences between groups, Duncan's multiple range test was used. The results were considered significant when the $P$-value was lower than 0.05 .

\section{RESULTS}

\section{Long-Term Experiment}

SNX rats were treated with R-568 or vehicle for 12 weeks and compared with vehicle-treated sham-op rats.

\section{Animal Data}

The heart weight and the LV weight were significantly higher in SNX than those in sham-op animals and were not influenced by the treatment (Table 1). Serum creatinine was significantly increased in all SNX groups compared with sham-op, with no difference between the treatment groups.

At the end of this study, $24 \mathrm{~h}$-post-dose, plethysmographically measured systolic blood pressure was higher in all SNX groups than that in sham-op animals.

The serum angiotensin II concentration was significantly higher in SNX treated with vehicle or R-568 than that in sham-op.

Albumin excretion was increased in all SNX groups at 12 weeks after operation compared with that in sham-op animals. Albuminuria was highest in the vehicle-treated SNX group but was significantly lower in the SNX + R-568 group.

\section{Calcium and Phosphorus Metabolism}

At $24 \mathrm{~h}$ post-dose, there was no longer a significant difference in the serum calcium concentration between the groups (Table 2). The phosphorus concentration was significantly higher in the SNX group treated with vehicle and R-568 than that in sham-op animals. The calcium-phosphate product $(\mathrm{Ca} \times \mathrm{P})$ was increased in parallel. Serum PTH concentration was significantly increased in the untreated SNX group compared with that in sham-op animals, but was lower in the SNX + R-568 group.

\section{Decreased Fibrosis and Capillary Rarefaction in Myocardium after Treatment with R-568}

In this 12-week experiment, the capillary length density $\left(\mathrm{L}_{\mathrm{V}}\right)$ was significantly lower, and the mean intercapillary distance was significantly higher, in untreated SNX animals than those in sham-op animals (Figure 1a and b), but the values were not different from the 4-week experiment, suggesting that cardiac remodeling had come to a standstill. Similarly, capillary $\mathrm{L}_{\mathrm{V}}$ was significantly higher and mean intercapillary distance significantly lower in SNX animals treated with R-568 than those in untreated SNX animals. 
Table 1 Animal data, blood pressure at study end, serum biochemistry, and albumin excretion rate (long-term experiment)

\begin{tabular}{|c|c|c|c|c|c|c|c|c|}
\hline Group & $\begin{array}{l}\text { Body weight } \\
\text { (g) }\end{array}$ & $\begin{array}{l}\text { Heart/body } \\
\text { weight } \\
\text { ratio (\%) }\end{array}$ & $\begin{array}{l}\text { LV weight } \\
\text { (g) }\end{array}$ & $\begin{array}{l}\text { Systolic blood } \\
\text { pressure } \\
(\mathrm{mm} \mathrm{Hg})\end{array}$ & $\begin{array}{l}\text { Serum creatinine } \\
\text { (mg per } 100 \mathrm{ml} \text { ) }\end{array}$ & $\begin{array}{c}\text { Serum } \\
\text { angiotensin } \\
\text { II (ng/ml) }\end{array}$ & $\begin{array}{l}\text { Albumin } \\
\text { excretion } \\
\text { at week } 4 \\
\text { (mg/24 h) }\end{array}$ & $\begin{array}{l}\text { Albumin } \\
\text { excretion } \\
\text { at week } 12 \\
(\mathrm{mg} / 24 \mathrm{~h})\end{array}$ \\
\hline Sham-op+vehicle $(n=16)$ & $569 \pm 98$ & $0.34 \pm 0.12$ & $0.83 \pm 0.27$ & $129 \pm 21$ & $0.53 \pm 0.08$ & $5.9 \pm 4.6$ & $0.4 \pm 0.5$ & $0.4 \pm 0.2$ \\
\hline SNX+vehicle $(n=17)$ & $484 \pm 63^{*}$ & $0.58 \pm 0.09^{*}$ & $1.35 \pm 0.31^{*}$ & $164 \pm 12^{*}$ & $1.05 \pm 0.36^{*}$ & $30.1 \pm 13.1^{*}$ & $15.3 \pm 7.7^{*}$ & $39.0 \pm 24.8^{*}$ \\
\hline ANOVA & $P<0.001$ & $P<0.001$ & $P<0.001$ & $P<0.001$ & $P<0.001$ & $P<0.005$ & $P<0.001$ & $P<0.001$ \\
\hline
\end{tabular}

ANOVA, analysis of variance; sham-op, sham operation; SNX, subtotal nephrectomy.

Significant differences vs * sham-op+vehicle; ${ }^{\dagger} S N X+$ vehicle.

${ }^{\mathrm{a}}$ At $24 \mathrm{~h}$ after dose.

Table 2 Serum calcium, phosphate, and PTH concentrations $24 \mathrm{~h}$ after dose (long-term experiment)

\begin{tabular}{lcccc}
\hline Group & $\begin{array}{c}\text { Serum } \\
\text { calcium } \\
(\mathrm{mmol} / \mathrm{l})\end{array}$ & $\begin{array}{c}\text { Serum } \\
\text { phosphate } \\
(\mathrm{mmol} / \mathrm{l})\end{array}$ & $\begin{array}{c}\mathrm{Ca} \times \mathrm{P} \text { product } \\
\left(\mathrm{mmol}^{2} / \mathrm{I}^{2}\right)\end{array}$ & $\begin{array}{c}\mathrm{PTH} \\
(\mathrm{pg} / \mathrm{ml})\end{array}$ \\
\hline Sham-op+vehicle & $2.61 \pm 0.15$ & $2.33 \pm 0.28$ & $6.05 \pm 0.88$ & $100 \pm 26$ \\
SNX+vehicle & $2.66 \pm 0.26$ & $2.84 \pm 0.52^{*}$ & $7.48 \pm 1.42^{*}$ & $403 \pm 200^{*}$ \\
SNX+R-568 & $2.65 \pm 0.22$ & $2.48 \pm 0.29^{\dagger}$ & $6.59 \pm 0.97$ & $110 \pm 43^{\dagger}$ \\
& & & & \\
ANOVA & NS & $P=0.006$ & $P=0.014$ & $P<0.001$
\end{tabular}

ANOVA, analysis of variance; $\mathrm{Ca}$, calcium; NS, not significant; $\mathrm{P}$, phosphorous; PTH, parathyroid hormone; sham-op, sham operation; SNX, subtotal nephrectomy.

Significant differences $v s{ }^{*}$ sham-op+vehicle; ${ }^{\dagger} \mathrm{SNX}+$ vehicle.

The volume densities of interstitial matrix and of fibrocytes were again significantly higher in untreated SNX animals than those in sham-op or in SNX treated with calcimimetic animals (Figure 1c).

The total collagen area (given as Sirius-red-positive area) was significantly higher in vehicle-treated SNX animals than that in sham-op animals (Figure 1d). The collagen area was significantly lower in SNX treated with R-568 than that in vehicle-treated SNX animals.

\section{Increased Expression of CaSR after Treatment with R-568}

Both CaSR protein expression, assessed with immunohistochemistry and confirmed by western blotting, and mRNA transcript expression, assessed by in situ hybridization, were significantly higher in SNX + R-568 animals than those in the respective animals treated with vehicle (Figure 2).

\section{Markers of Fibrosis}

The staining for prolyl-4-hydroxylase, a marker for collagensynthesizing cells, was not significantly different between study groups (score: $0.94 \pm 0.29$ in sham-op, $1.33 \pm 0.27$ in $\mathrm{SNX}+$ vehicle, and $1.36 \pm 0.44$ in SNX + R-568).

Collagen I and III deposition in myocardium (Figure $3 \mathrm{a}$ and b) was significantly higher in the untreated SNX animals than that in sham-op and SNX + R-568 animals.

The expression of MMP-1 was significantly lower in vehicle-treated SNX animals than that in sham-op, but higher in SNX + R-568 animals compared with vehicletreated SNX animals (Figure 3c).

The expression of TIMP-1 was significantly higher in vehicle-treated SNX compared with that in sham-op and significantly lower in SNX + R-568 compared with SNX + vehicle (Figure 3d).

No difference in the expression of TIMP-2 was found between the groups (Figure 3e).

The protein expression of $T G F-\beta_{1}$ was significantly increased in untreated SNX compared with that in sham-op animals, and this was diminished by treatment with R-568 in SNX animals (Figure 3f). The same results were observed by immunostaining.

There was no difference in staining for TGF- $\beta$ receptor 1 (score: $2.57 \pm 0.71$ in sham-op, $2.01 \pm 0.25$ in SNX + vehicle, and $2.56 \pm 0.54$ in SNX $+\mathrm{R}-568)$ and TGF- $\beta$ receptor 2 (score: $1.96 \pm 0.49$ in sham-op, $2.15 \pm 0.73$ in SNX + vehicle, and $2.12 \pm 0.75$ in SNX + R-568) between the groups.

\section{Modified Activation of MAP Kinases after Treatment with R-568}

The expression of phosphorylated ERK-1/2 (p-ERK-1/2) was significantly higher in SNX rats treated with R-568 than that in sham-op and vehicle-treated SNX rats (Figure 4a).

The expression of phosphorylated p38 ( $p$-p38) was significantly higher in SNX + R-568 and sham-op animals than that in SNX treated with vehicle (Figure 4b). 

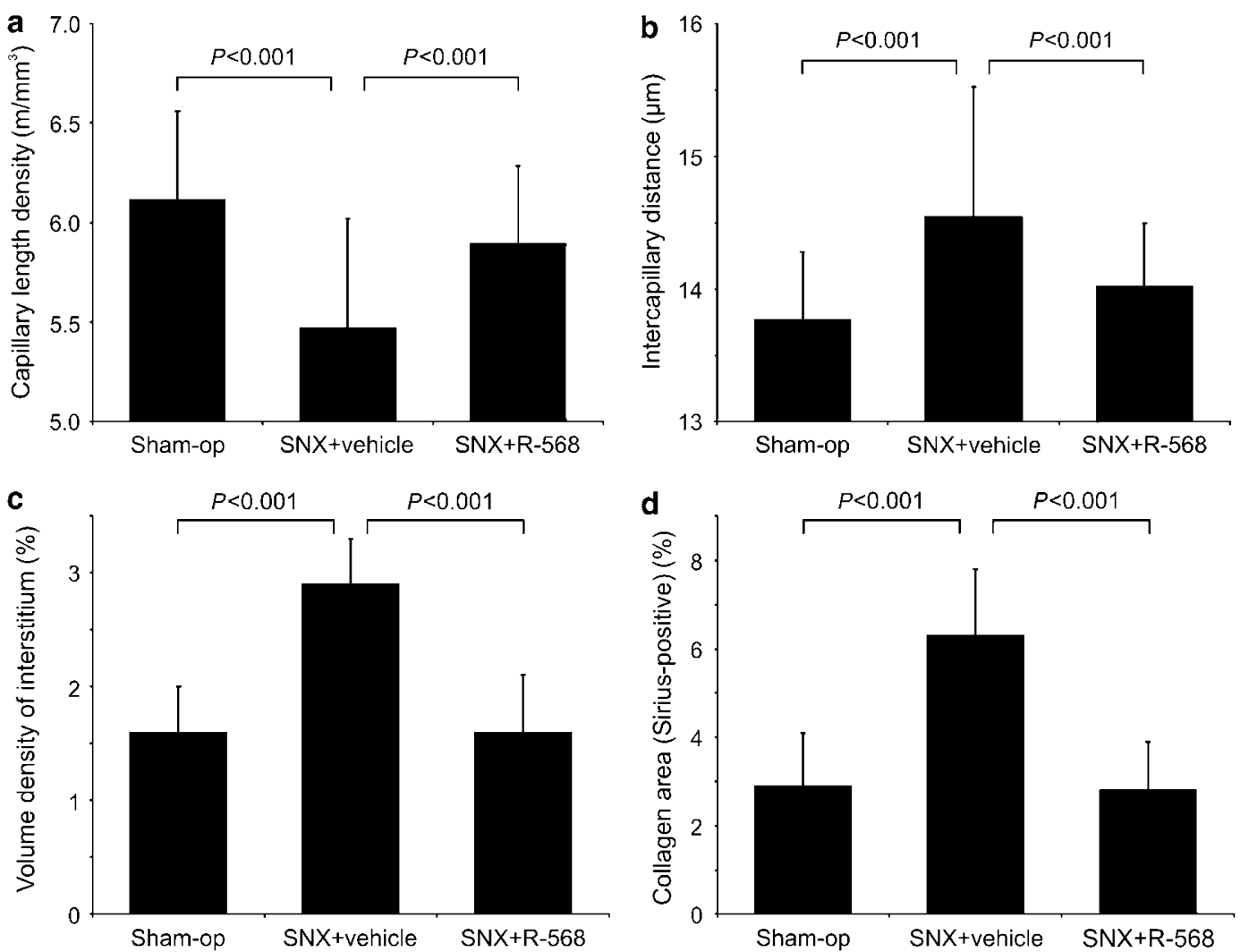

Figure 1 (a) Capillary length density, (b) mean intercapillary distance, (c) volume density of interstitium, and (d) collagen area at week 12.

The expression of phosphorylated JNK ( $p-J N K)$ was significantly lower in SNX + vehicle animals than that in shamop, and this was prevented by R-568 (Figure 4c).

\section{Markers of Endothelial Dysfunction and Oxidative Stress}

Staining for $V E G F$ was significantly more marked in untreated SNX and SNX + R-568 compared with that in shamop animals. The results were confirmed by western blotting (Figure 5a).

The expression of the VEGF receptor type 1 (flt-1) showed no significant differences between the study groups (Figure 5b, d-f).

Significantly weaker staining for VEGF receptor type 2 (flk-1) was observed in untreated SNX compared with that in sham-op (Figure 5c, g-i). Treatment with R-568 resulted in stronger staining for $f l k-1$ in SNX animals compared with that in untreated SNX.

The staining for nitrotyrosine, a marker of oxidative stress, was significantly increased in untreated SNX compared with that in sham-op animals, but was significantly reduced in SNX + R-568 compared with untreated SNX (Figure 6).

The expressions of eNOS and iNOS were significantly lower in vehicle-treated SNX than those in sham-op animals. They were significantly higher in SNX treated with R-568 than that in vehicle-treated SNX (Figure 7a and b).
The expression of HIF- $1 \alpha$ was significantly lower in SNX treated with R-568 than that in vehicle-treated SNX and in sham-op animals (Figure 7c).

No significant difference in the expression of heat shock protein 70 (Hsp-70) was observed between the groups (data not shown).

\section{Short-Term Experiment}

To exclude potential confounding by differences in food consumption, calcimimetic-treated and vehicle-treated SNX groups were compared in a short-term experiment.

The final body weight was significantly $(P<0.001)$ lower in R-568-treated SNX $(331 \pm 19 \mathrm{~g})$ than that in vehicle-treated SNX $(375 \pm 28 \mathrm{~g})$ and in sham-op $(386 \pm 9 \mathrm{~g})$ despite equal food intake. The heart weight and the ratio of heart and body weight were not significantly different between SNX treated with R-568 and with vehicle (data not shown). Serum ionized calcium 2-h after dose was significantly $(P<0.001)$ lower in SNX + R-568 $(1.11 \pm 0.05 \mathrm{mmol} / \mathrm{l})$ than that in SNX + vehicle $(1.32 \pm 0.04)$ and in sham-op $(1.38 \pm 0.05)$. Hematocrit was not significantly different between R-568 $(46.5 \pm 1.4 \%)$ and vehicle $(46.9 \pm 1.8 \%)$ treated SNX groups, and significantly $(P=0.022)$ lower in both SNX groups compared with that in sham-op $(49.6 \pm 3.0 \%)$. Systolic blood pressure, measured intraaortally $2 \mathrm{~h}$ after dose, was significantly $(P<0.001)$ higher in 
a

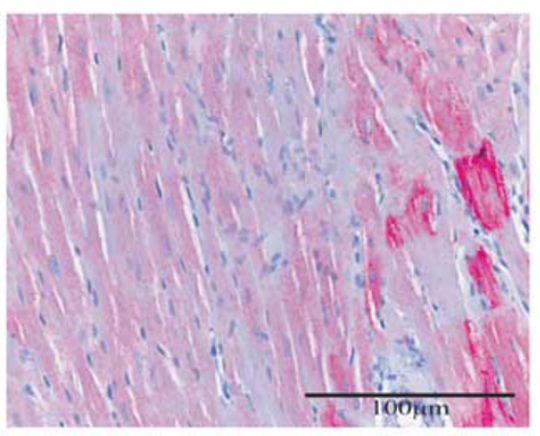

d

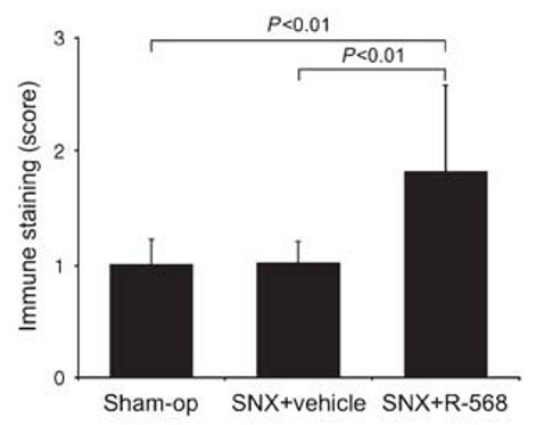

b

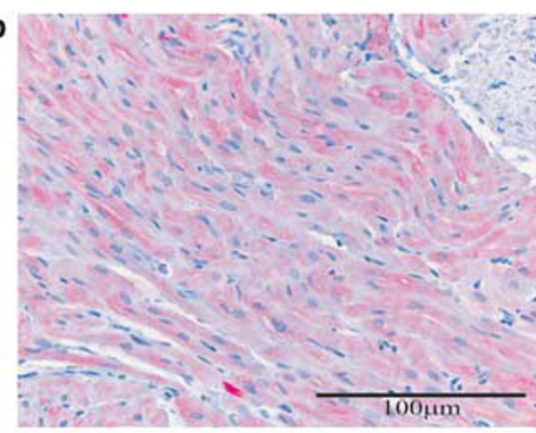

e

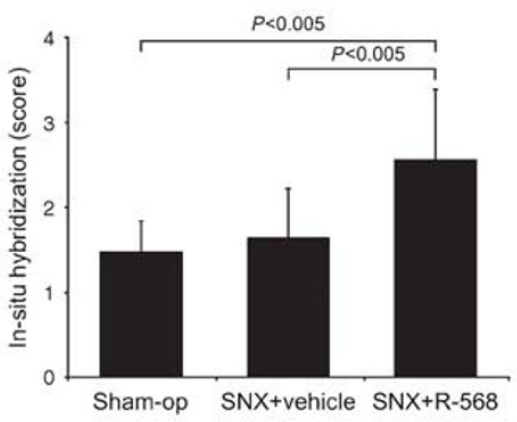

c

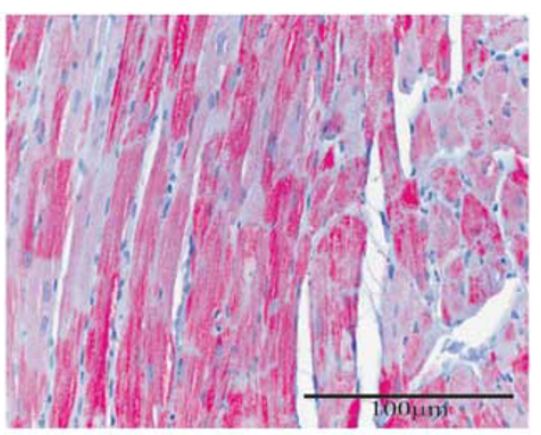

$\mathbf{f}$
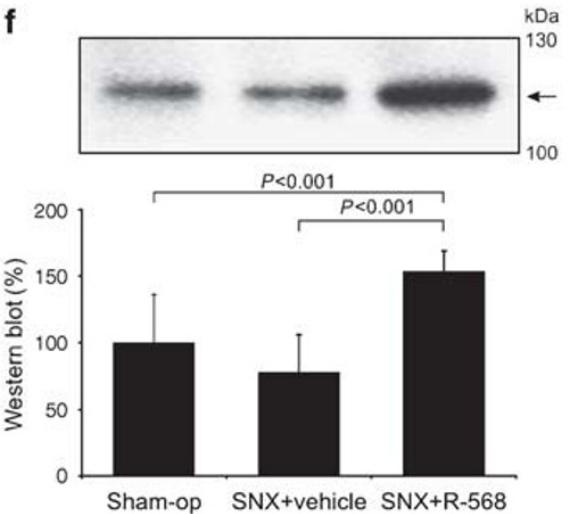

Figure 2 Representative pictures of the immune staining for CaSR in (a) sham-op, (b) SNX + vehicle, (c) and SNX + R-568. Original magnification $\times 400$. (d) Quantitation of CaSR immune staining, (e) CaSR in situ hybridization, and (f) representative CaSR western blots at week 12.

a $\mathrm{kDa}$
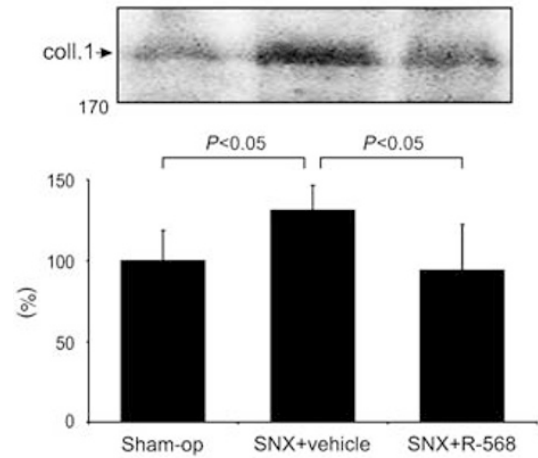

d $\mathrm{kDa}$
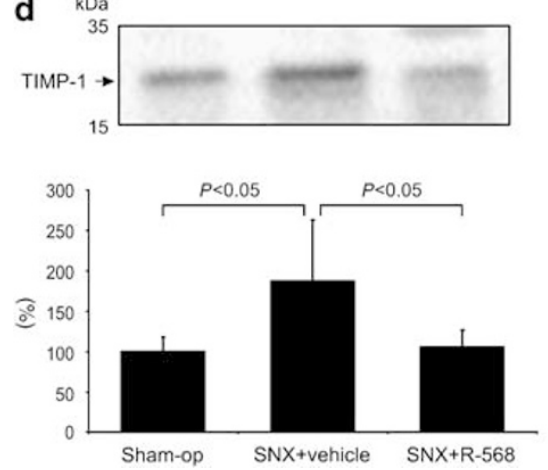

b
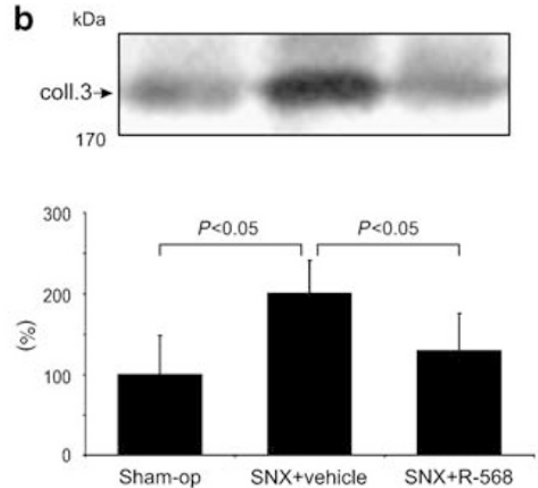

e $\mathrm{kDa}$
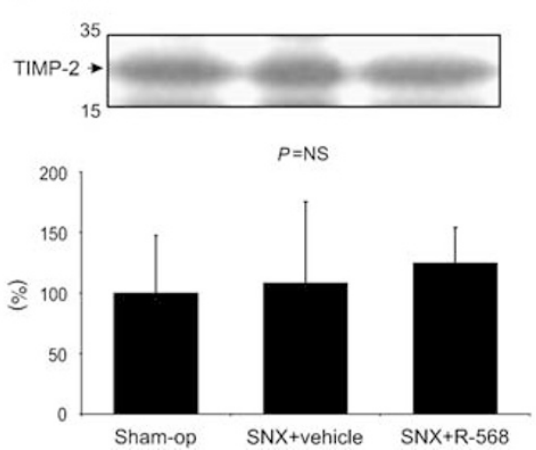

C $\mathrm{kDa}$
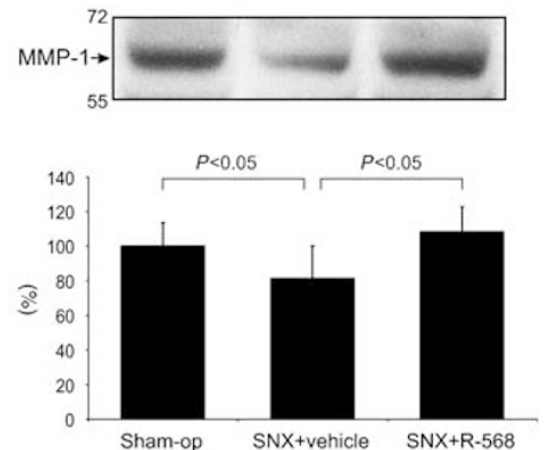

f $k D a$

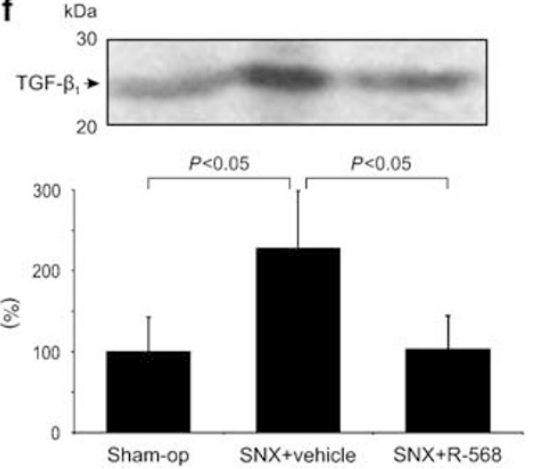

Figure 3 Representative western blots for (a) collagen I, (b) collagen III, (c) MMP-1, (d) TIMP-1, (e) TIMP-2, and (f) TGF- $\beta_{1}$ at week 12. 
a
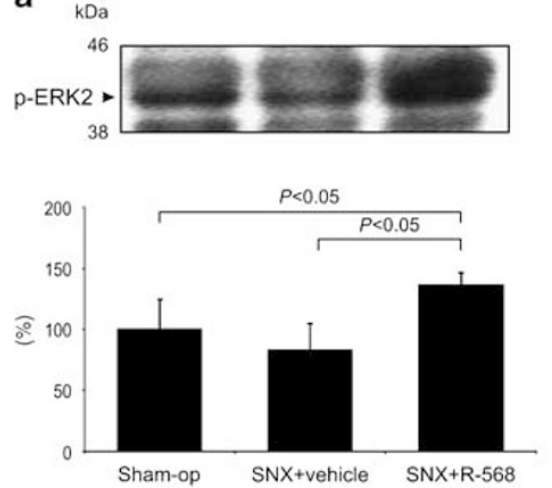

b
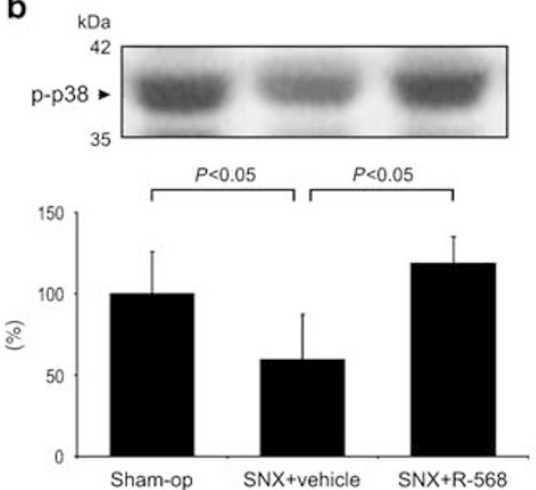

C
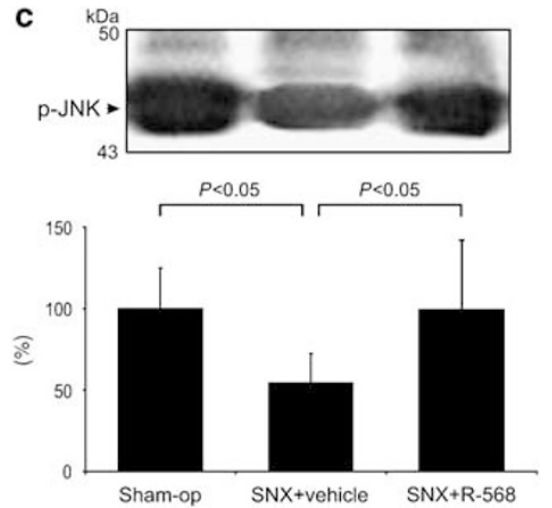

Figure 4 Representative western blots of myocardium for (a) p-ERK-1/2, (b) p-p38, and (c) p-JNK at week 12.
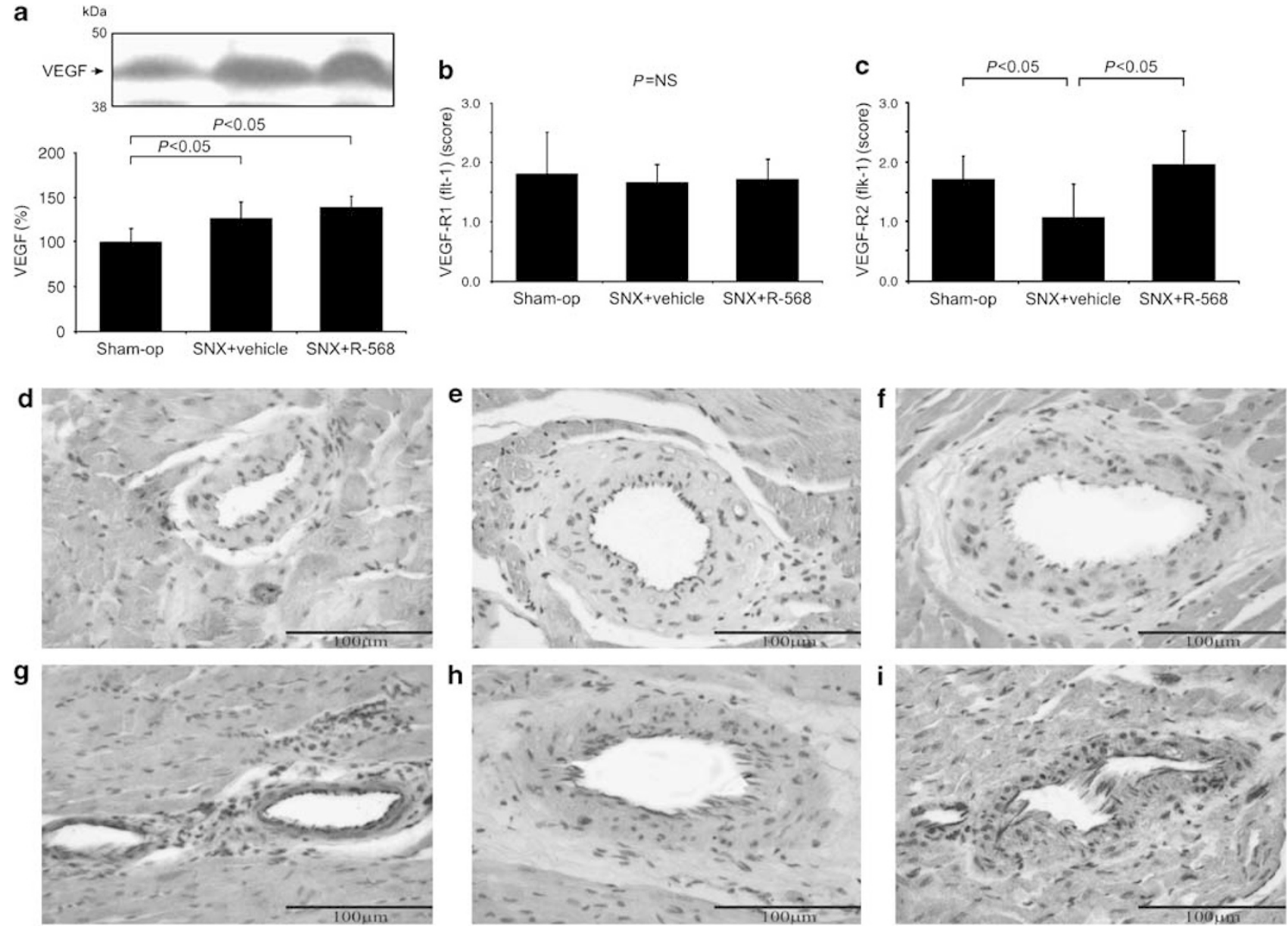

Figure 5 Representative western blots of myocardium for (a) VEGF, (b) evaluation of immune staining for VEGF-R1, and (c) VEGF-R2 at week 12. Representative pictures of staining for VEGF-R1 in (d) sham-op, (e) SNX + vehicle, and (f) SNX + R-568 and for VEGF-R2 in (g) sham-op, (h) SNX + vehicle, and (i) $\mathrm{SNX}+\mathrm{R}-568$.

SNX + vehicle $(162 \pm 16 \mathrm{~mm} \mathrm{Hg})$ than that in sham-op $(144 \pm 13)$ and $\mathrm{SNX}+\mathrm{R}-568(132 \pm 10)$. Urinary albumin excretion was significantly $(P<0.001)$ lower in SNX $+\mathrm{R}-568$ $(2.1 \pm 0.9 \mu \mathrm{g} / 24 \mathrm{~h})$ than that in SNX + vehicle $(4.5 \pm 2.2)$, but still higher when compared with that in sham-op $(0.5 \pm 0.3)$.
Echocardiography showed significantly lower FS\% in SNX + vehicle than that in sham-op. This was not seen in SNX-treated with R-568 (Figure 8). The thickness of interventricular septum was significantly higher in vehicletreated SNX $(1.67 \pm 0.09 \mathrm{~mm})$ than that in sham-op 

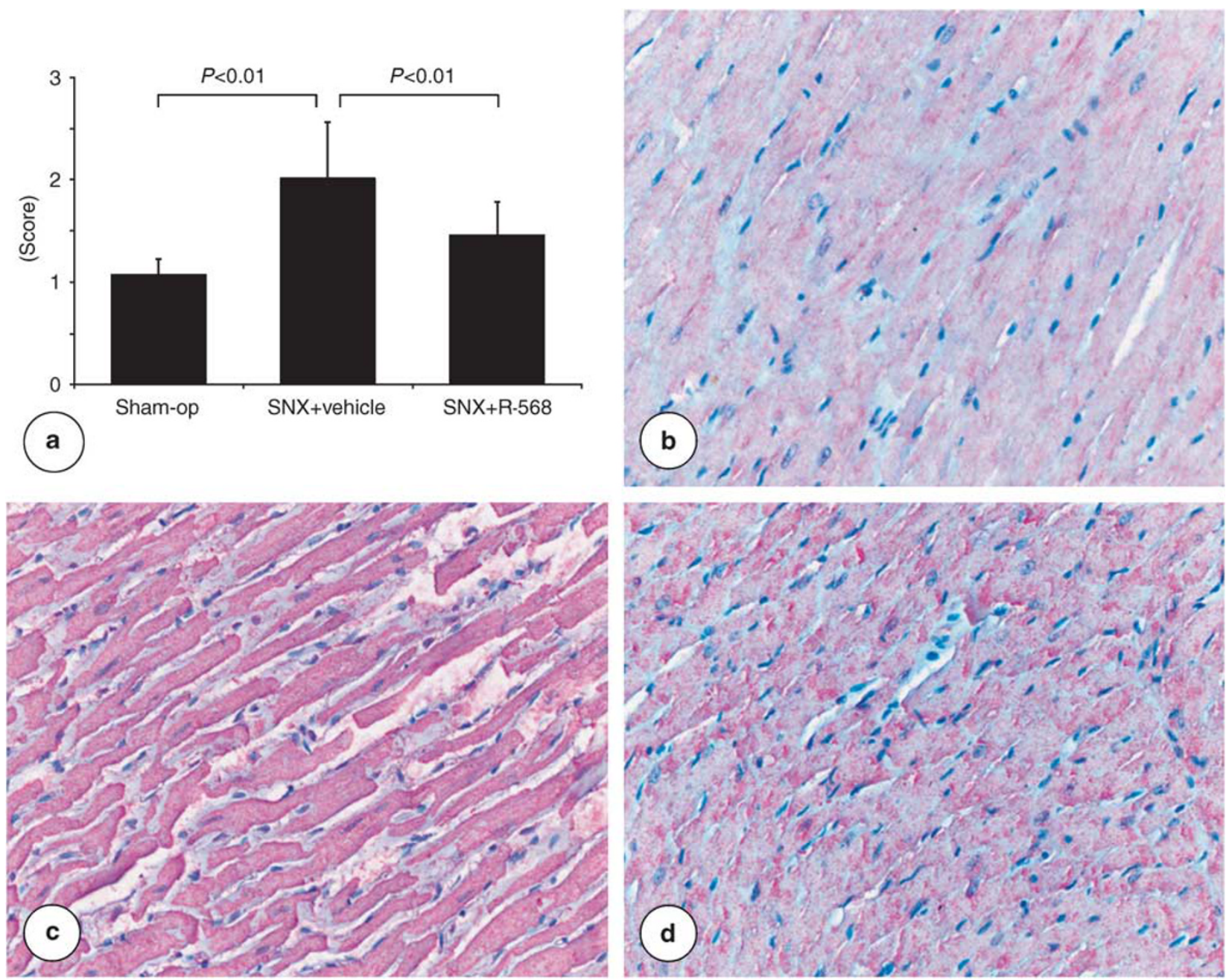

Figure 6 Evaluation of immune staining for (a) nitrotyrosine at week 12 and representative pictures in (b) sham-op, (c) SNX + vehicle, and (d) SNX + R-568.
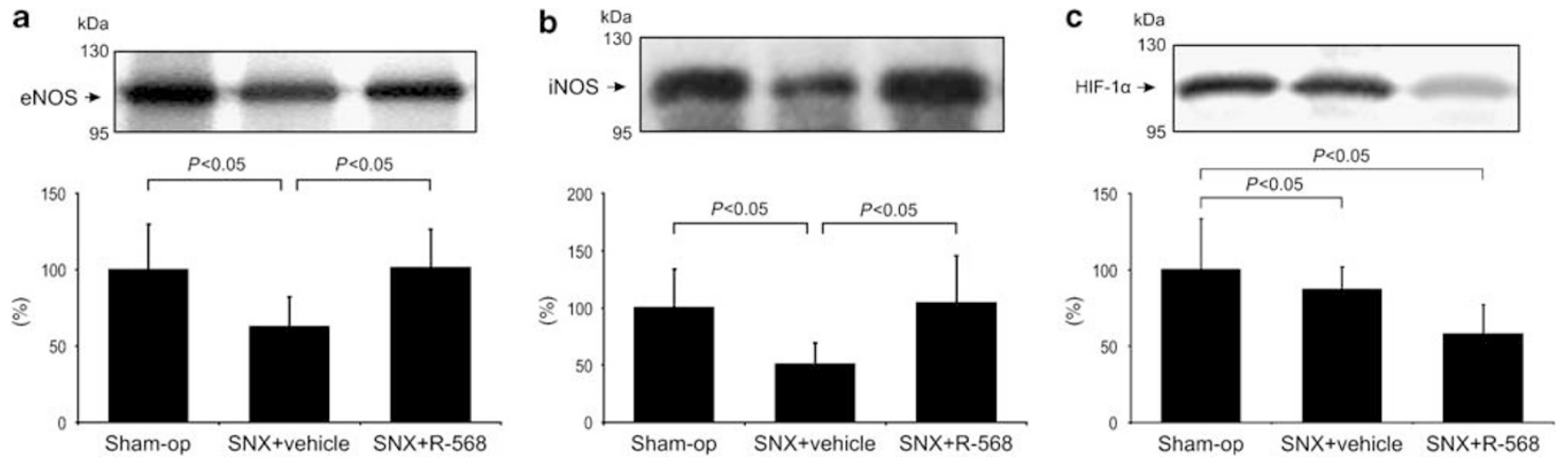

Figure 7 Representative western blots of myocardium for (a) eNOS, (b) iNOS, and (c) HIF-1 $\alpha$ at week 12.

$(1.44 \pm 0.14)$ and not significantly different in SNX $+\mathrm{R}-568$ $(1.56 \pm 0.21)$ compared with that in the two other groups. The heart was dilated in vehicle-treated SNX (LVEDD $5.07 \pm 0.84 \mathrm{~mm}$, LVESD $1.26 \pm 0.24 \mathrm{~mm}$ ) compared with that in sham-op (LVEDD $4.52 \pm 0.33 \mathrm{~mm}, \quad$ LVESD
$0.89 \pm 0.14 \mathrm{~mm}$ ) and in SNX + R568 (LVEDD $4.28 \pm 0.79 \mathrm{~mm}$, LVESD $0.93 \pm 0.20 \mathrm{~mm}$ ).

In both the right and the left ventricle, the capillary $\mathrm{L}_{\mathrm{v}}$ was significantly lower, and the mean intercapillary distance (as an index of interstitial tissue) was higher in SNX + vehicle 

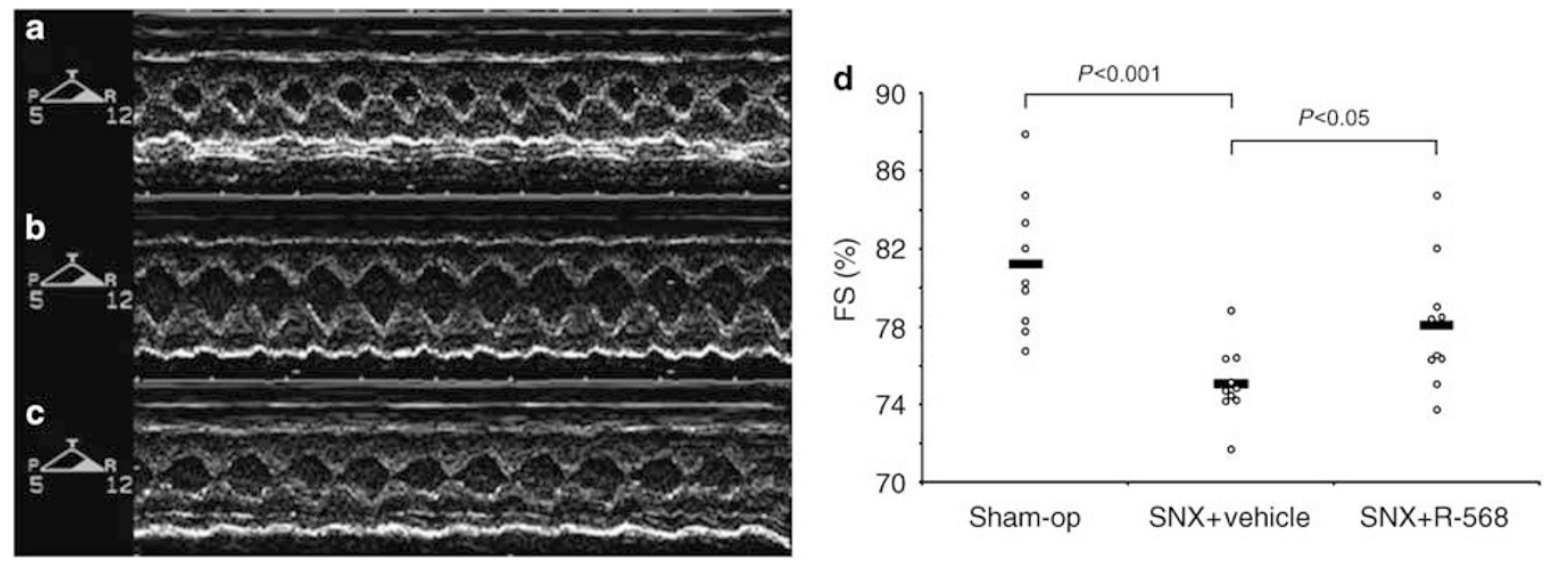

Figure 8 Echocardiography at week 4: representative pictures from (a) sham-op, (b) SNX + vehicle, and (c) SNX + R-568, and (d) FS\% values.

than that in sham-op. These changes were prevented in SNX animals treated with R-568 (Figure 9).

In summary, the calcimimetic agent R-568 reduced the capillary deficit (microvessel disease) and the expansion of interstitium (interstitial fibrosis) in the myocardium despite no effect on heart hypertrophy. The capillary deficit was observed in SNX both in the left and the right ventricle myocardium and was improved after treatment with R-568. Moreover, the contractile function of the left ventricle in SNX was improved by R-568. The increased collagen deposition in myocardium was most probably because of diminished degradation rather than enhanced synthesis and the capillary deficit was most probably because of resistance to increased VEGF.

\section{DISCUSSION}

In this study, the calcimimetic R-568 reduced the capillary deficit (microvessel disease) and the expansion of interstitium (interstitial fibrosis) in the myocardium despite no effect on heart hypertrophy. In parallel to the prevention of cardiac remodeling, calcimimetic treatment prevented deterioration of the contractile function of the heart in SNX rats as measured $24 \mathrm{~h}$ after dose.

Although a beneficial effect of calcimimetics on heart morphology had been suggested in the past, ${ }^{14}$ it was not clear which mechanisms were involved. To address this issue, we investigated the effects of the calcimimetic R-568 on heart morphology and key molecules in the pathogenesis of cardiomyopathy in subtotally nephrectomized rats.

We observed no effect of the calcimimetic on LV hypertrophy (LVH), which is in contrast to several small studies showing a reduction of LVH in patients with end-stage renal disease treated to decrease $\mathrm{PTH} .{ }^{24}$ It is unclear whether this is explained by species differences or study protocols. Blood pressure is not likely to be a major confounder. Within the limitation of the method, the intervention failed to significantly affect blood pressure. The effect of calcimimetics on blood pressure that had been observed in this laboratory using telemetry ${ }^{25}$ was not observed in this study using tail plethysmography (in the long-term experiment), but was seen by intra-aortic measurement $2 \mathrm{~h}$ after dose in a shortterm setting. Therefore, the effect on BP is apparently rather transient.

Another argument against the crucial role of elevated systemic blood pressure in the observed myocardial remodeling is the observation of a similar capillary deficit and intercapillary distance in the left and the right ventricle of untreated SNX. The capillary rarefaction and expansion of interstitial space were equally prevented in both ventricles by the calcimimetic.

Cardiac hypertrophy begins as a compensatory response to external stressors. When the stressors persist, compensatory hypertrophy leads to myocardial remodeling and contractile dysfunction. ${ }^{26,27}$ Mitogen-activated protein kinase (MAPK) activity plays an important role in heart hypertrophy. ${ }^{28}$ Holstein ${ }^{29}$ showed that activation of the CaSR activates ERK$1 / 2$ kinases. The ERK-1/2 signaling was shown to promote adaptive hypertrophy with normalized wall stress and compensation for increased load. ${ }^{30,31}$ Our study documented that R-568 increased ERK-1/2 activation. As the LVH was unaltered, one might argue that the treatment did not prevent the cardiac hypertrophy but shifted the signaling toward adaptive growth instead of fibrosis. This is also supported by our results of heart function analysis. Inhibition of ERK activation was shown to exaggerate cardiac injury. ${ }^{32}$ In agreement with that observation, increased ERK activation in treated animals accompanied improved heart morphology. The activation of both ERK and JNK pathways are thought to protect cardiomyocytes from apoptosis, although the role of p38 remains unclear. ${ }^{28}$ We observed a lower expression of phosphorylated JNK and p38 in vehicle-treated SNX; this was prevented by R-568. One can speculate that normalization of JNK and p38 activation combined with the activation of ERK by the CaSR cause cardioprotection in this model. Inhibition of p38 MAPK was shown to improve the cardiac function in models with increased p38 activation. ${ }^{33,34}$ On the contrary, 

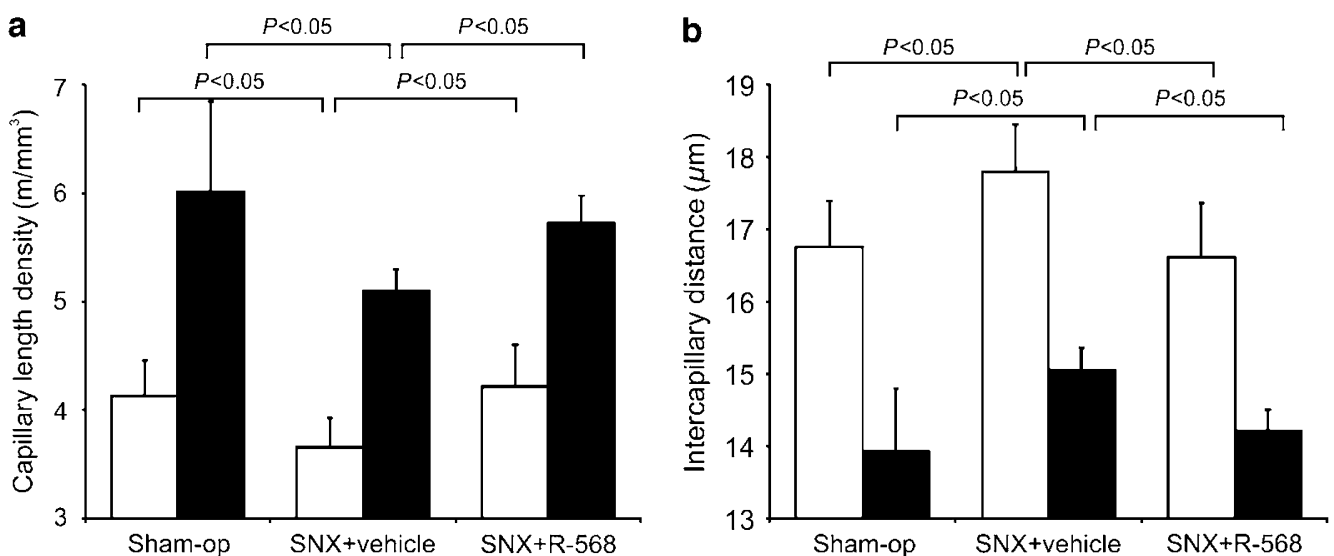

Figure 9 (a) Capillary length density and (b) intercapillary distance in the right ( $\square$ ) and the left ( $\mathbf{\square}$ ) ventricle of pair-fed animals at week 4.

the inhibition of JNK has an opposite effect. ${ }^{34}$ One may argue that the CaSR signaling improved the cardiac function in our model by restoring the balance between the MAPK.

Repeated or prolonged injury induces sustained TGF- $\beta$ overproduction leading to the progressive deposition of extracellular matrix and tissue fibrosis. ${ }^{35}$ Blocking the TGF- $\beta$ signaling was shown to prevent the deposition of extracellular matrix in different tissues. ${ }^{35}$ It is worth noting that TGF- $\beta_{1}$ expression was increased in untreated SNX and partially reversed by the calcimimetic. The expression of both types 1 and 2 TGF- $\beta$ receptors was not changed in uremia consistent with the observation of increased signaling.

The increase in collagen fiber deposition in the cardiac interstitium has important functional consequences, particularly diastolic malfunction and electric instability. In this model, increased amounts of both collagen type I and type III were deposited in untreated SNX, and this was abrogated by the calcimimetic. Lower expression of MMP-1 and higher abundance of TIMP-1 in vehicle-treated SNX suggest slower degradation of collagen as observed in patients with hypertension and chronic heart failure. ${ }^{36}$ The treatment with R-568 normalized TIMP- 1 and MMP- 1 , and this may explain the prevention of fibrosis in our model. The unaltered expression of prolyl-4-hydroxylase in our model suggests that the increased collagen deposition in myocardium was because of diminished degradation rather than enhanced synthesis.

Although the role of PTH in the genesis of interstitial fibrosis had been observed before, ${ }^{11}$ its role in the genesis of capillary rarefaction-with potentially even greater functional significance-has not been appreciated so far. The precise mechanisms accounting for the lack of parallelism between capillary growth and cardiomyocyte enlargement in the development of uremic cardiomyopathy are unknown. The expression of VEGF was significantly increased in this study, suggesting problems with VEGF signal transduction as the cause of inadequate capillary growth. This was further supported by downregulation of the VEGF receptor flk-1 in the myocardium of uremic rats. This explanation would be similar to the observation of Sasso et $\mathrm{al}^{37}$ in diabetic patients. Hypoxemia, through the HIF sensor, is a powerful stimulant of VEGF synthesis. This does not seem to be responsible for high VEGF, because HIF- $1 \alpha$ was even lower in uremic animals.

It is not clear whether the reduction of flk-1 is a cause of capillary loss or whether it reflects the diminished surface of endothelium in the hearts of uremic animals. Our observation that the expressions of both flk-1 and eNOS were parallel to the amount of capillaries in the myocardium indicates that these changes are secondary to the changes in endothelial surface. On the contrary, the expression of another VEGF receptor, flt-1, was unaltered, arguing against a simple change in the endothelial mass as a determinant of the expression of VEGF receptors.

The common denominator in the genesis of cardiac remodeling of uremic cardiomyopathy is increased oxidative stress. ${ }^{38}$ Oxidative stress, as indicated by staining for nitrotyrosine, was increased in the heart of uremic animals and was diminished by the calcimimetic. Little had so far been known about the effects of calcimimetics on oxidative stress in the heart. We have shown that treatment with the calcimimetic reduced staining for nitrotyrosine and normalized the expression of eNOS and iNOS in the heart of uremic rats.

One potential determinant of the action of calcimimetics is the level of expression of CaSR. ${ }^{39}$ The CaSR is expressed by cardiomyocytes. ${ }^{40}$ Although in uremia, the CaSR expression is reduced in the parathyroid gland, ${ }^{41}$ it was not altered in the myocardium after SNX. Similar to what is seen in the parathyroid glands, ${ }^{42}$ the CaSR expression was increased in this study after administration of the calcimimetic.

Changed activity of the renin-angiotensin system is another potential confounder of the observed effects of the calcimimetic. Although calcimimetics had been shown to decrease renin release in vitro, ${ }^{43}$ we did not observe lower systemic angiotensin II levels in SNX animals treated with R-568. 
In summary, correction of hyperparathyroidism by a calcimimetic in experimental uremia failed to abrogate LVH, but significantly interfered with the development of both interstitial fibrosis and microvessel disease.

\section{ACKNOWLEDGEMENTS}

The skillful technical assistance of Zlata Antoni, Peter Rieger, Heike Ziebart, Antje Habel, Annett Mueller, and Monika Weckbach is gratefully acknowledged. N Koleganova and G Piecha were supported by fellowships of the International Society of Nephrology. The study was supported by Collegium Nephrologicum e.V., Heidelberg. R-568 was provided and the study was supported financially by Amgen Inc

1. Dennis VW. Coronary heart disease in patients with chronic kidney disease. J Am Soc Nephrol 2005;16:S103-S106.

2. Sarnak MJ, Levey AS, Schoolwerth AC, et al. Kidney disease as a risk factor for development of cardiovascular disease: a statement from the American Heart Association Councils on Kidney in Cardiovascular Disease, High Blood Pressure Research, Clinical Cardiology, and Epidemiology and Prevention. Circulation 2003;108:2154-2169.

3. Tyralla $\mathrm{K}$, Amann K. Morphology of the heart and arteries in renal failure. Kidney Int 2003;63:580-S83.

4. Amann K, Breitbach M, Ritz E, et al. Myocyte/capillary mismatch in the heart of uremic patients. J Am Soc Nephrol 1998;9:1018-1022.

5. Amann K, Kronenberg G, Gehlen F, et al. Cardiac remodelling in experimental renal failure-an immunohistochemical study. Nephrol Dial Transplant 1998;13:1958-1966.

6. Slatopolsky $E$, Brown A, Dusso A. Pathogenesis of secondary hyperparathyroidism. Kidney Int 1999;56:S14-S19.

7. Kestenbaum B, Andress DL, Schwartz SM, et al. Survival following parathyroidectomy among United States dialysis patients. Kidney Int 2004;66:2010-2016.

8. Foley RN, Li S, Liu J, et al. The fall and rise of parathyroidectomy in U.S. hemodialysis patients, 1992-2002. J Am Soc Nephrol 2005;16:210-218.

9. Smogorzewski M, Perna AF, Borum PR, et al. Fatty acid oxidation in the myocardium: effects of parathyroid hormone and CRF. Kidney Int 1988;34:797-803.

10. Baczynski R, Massry SG, Kohan R, et al. Effect of parathyroid hormone on myocardial energy metabolism in the rat. Kidney Int 1985;27:718-725.

11. Amann K, Ritz E, Wiest $G$, et al. A role of parathyroid hormone for the activation of cardiac fibroblasts in uremia. J Am Soc Nephrol 1994;4:1814-1819.

12. Amann K, Tornig J, Flechtenmacher $\mathrm{C}$, et al. Blood-pressureindependent wall thickening of intramyocardial arterioles in experimental uraemia: evidence for a permissive action of PTH. Nephrol Dial Transplant 1995;10:2043-2048.

13. Nagano N. Pharmacological and clinical properties of calcimimetics: calcium receptor activators that afford an innovative approach to controlling hyperparathyroidism. Pharmacol Ther 2006;109:339-365.

14. Ogata $H$, Ritz $E$, Odoni $G$, et al. Beneficial effects of calcimimetics on progression of renal failure and cardiovascular risk factors. J Am Soc Nephrol 2003;14:959-967.

15. Piecha G, Koleganova N, Gross ML, et al. Regression of glomerulosclerosis in subtotally nephrectomized rats: effects of monotherapy with losartan, spironolactone, and their combination. Am J Physiol Renal Physiol 2008;295:F137-F144.

16. Amann $\mathrm{K}$, Munter $\mathrm{K}$, Wessels $\mathrm{S}$, et al. Endothelin a receptor blockade prevents capillary/myocyte mismatch in the heart of uremic animals. J Am Soc Nephrol 2000;11:1702-1711.

17. Mattfeldt $\mathrm{T}$, Mall $\mathrm{G}$, Gharehbaghi $\mathrm{H}$, et al. Estimation of surface area and length with the orientator. J Microsc 1990;159:301-317.

18. Tornig J, Amann K, Ritz E, et al. Arteriolar wall thickening, capillary rarefaction and interstitial fibrosis in the heart of rats with renal failure: the effects of ramipril, nifedipine and moxonidine. J Am Soc Nephrol 1996;7:667-675.

19. Henquell L, Honig C. Intercapillary distances and capillary reserve in right and left ventricles: significance for control of tissue pO2. Microvasc Res 1976;12:35-41.
20. Tornig J, Gross M-L, Simonaviciene A, et al. Hypertrophy of intramyocardial arteriolar smooth muscle cells in experimental renal failure. J Am Soc Nephrol 1999;10:77-83.

21. Schwarz U, Amann K, Orth SR, et al. Effect of 1,25(OH)2 vitamin D3 on glomerulosclerosis in subtotally nephrectomized rats. Kidney Int 1998;53:1696-1705.

22. Bradford M. A rapid and sensitive method for the quantitation of microgram quantities of protein utilizing the principle of protein-dye binding. Anal Biochem 1976;72:248-254.

23. Sahn DJ, DeMaria A, Kisslo J, et al. Recommendations regarding quantitation in M-mode echocardiography: results of a survey of echocardiographic measurements. Circulation 1978;58:1072-1083.

24. Levin A, Li YC. Vitamin D and its analogues: do they protect against cardiovascular disease in patients with kidney disease? Kidney Int 2005;68:1973-1981.

25. Odenwald T, Nakagawa K, Hadtstein C, et al. Acute blood pressure effects and chronic hypotensive action of calcimimetics in uremic rats. J Am Soc Nephrol 2006;17:655-662.

26. Selvetella G, Hirsch E, Notte A, et al. Adaptive and maladaptive hypertrophic pathways: points of convergence and divergence. Cardiovasc Res 2004;63:373-380.

27. Hill JA, Olson EN. Cardiac plasticity. N Engl J Med 2008;358:1370-1380.

28. Wang Y. Mitogen-activated protein kinases in heart development and diseases. Circulation 2007;116:1413-1423.

29. Holstein DM, Berg KA, Leeb-Lundberg LMF, et al. Calcium-sensing receptor-mediated ERK1/2 activation requires G\{alpha\}i2 coupling and dynamin-independent receptor internalization. J Biol Chem 2004;279:10060-10069.

30. Opie LH, Commerford PJ, Gersh BJ, et al. Controversies in ventricular remodelling. Lancet 2006;367:356-367.

31. Bueno OF, De Windt LJ, Tymitz KM, et al. The MEK1-ERK1/2 signaling pathway promotes compensated cardiac hypertrophy in transgenic mice. EMBO J 2000;19:6341-6350.

32. Yue T-L, Wang C, Gu J-L, et al. Inhibition of extracellular signalregulated kinase enhances ischemia/reoxygenation-induced apoptosis in cultured cardiac myocytes and exaggerates reperfusion injury in isolated perfused heart. Circ Res 2000;86:692-699.

33. Li Z, Ma JY, Kerr I, et al. Selective inhibition of p38\{alpha\} MAPK improves cardiac function and reduces myocardial apoptosis in rat model of myocardial injury. Am J Physiol Heart Circ Physiol 2006;291:H1972-H1977.

34. Kyoi S, Otani H, Matsuhisa S, et al. Opposing effect of p38 MAP kinase and JNK inhibitors on the development of heart failure in the cardiomyopathic hamster. Cardiovasc Res 2006;69:888-898.

35. Border WA, Noble NA. Transforming growth factor $\beta$ in tissue fibrosis. N Engl J Med 1994;331:1286-1292.

36. Ahmed SH, Clark LL, Pennington WR, et al. Matrix metalloproteinases/ tissue inhibitors of metalloproteinases: relationship between changes in proteolytic determinants of matrix composition and structural, functional, and clinical manifestations of hypertensive heart disease. Circulation 2006;113:2089-2096.

37. Sasso FC, Torella D, Carbonara O, et al. Increased vascular endothelial growth factor expression but impaired vascular endothelial growth factor receptor signaling in the myocardium of type 2 diabetic patients with chronic coronary heart disease. J Am Coll Cardiol 2005;46:827-834.

38. Murdoch $C E$, Zhang $M$, Cave AC, et al. NADPH oxidase-dependent redox signalling in cardiac hypertrophy, remodelling and failure. Cardiovasc Res 2006;71:208-215.

39. Brown EM. The calcium-sensing receptor ( $\mathrm{CaR})$ and its disorders. Hormones (Athens) 2002;1:10-21.

40. Tfelt-Hansen J, Hansen JL, Smajilovic S, et al. Calcium receptor is functionally expressed in rat neonatal ventricular cardiomyocytes. Am J Physiol Heart Circ Physiol 2006;290:H1165-H1171.

41. Kifor $\mathrm{O}$, Moore Jr FD, Wang $\mathrm{P}$, et al. Reduced immunostaining for the extracellular $\mathrm{Ca}^{2+}$-sensing receptor in primary and uremic secondary hyperparathyroidism. J Clin Endocrinol Metab 1996;81:1598-1606.

42. Mizobuchi $\mathrm{M}$, Hatamura I, Ogata $\mathrm{H}$, et al. Calcimimetic compound upregulates decreased calcium-sensing receptor expression level in parathyroid glands of rats with chronic renal insufficiency. J Am Soc Nephrol 2004;15:2579-2587.

43. Ortiz-Capisano MC, Ortiz PA, Garvin JL, et al. Expression and function of the calcium-sensing receptor in juxtaglomerular cells. Hypertension 2007;50:737-743. 